THE JOURNAL OF PHILOSOPHICAL ECONOMICS:

REFLECTIONS ON ECONOMIC AND SOCIAL ISSUES

Volume XIV Issues 1-2

Spring-Autumn 2021

ISSN: $1843-2298$

EISSN: $1844-8208$

Publication date:

20 November 2021

Paper format: $16.5 \times 23.5 \mathrm{~cm}$

Copyright note:

Authors retain unrestricted copyright and all publishing rights in compliance with the Creative Commons license CC BY-NC-SA.
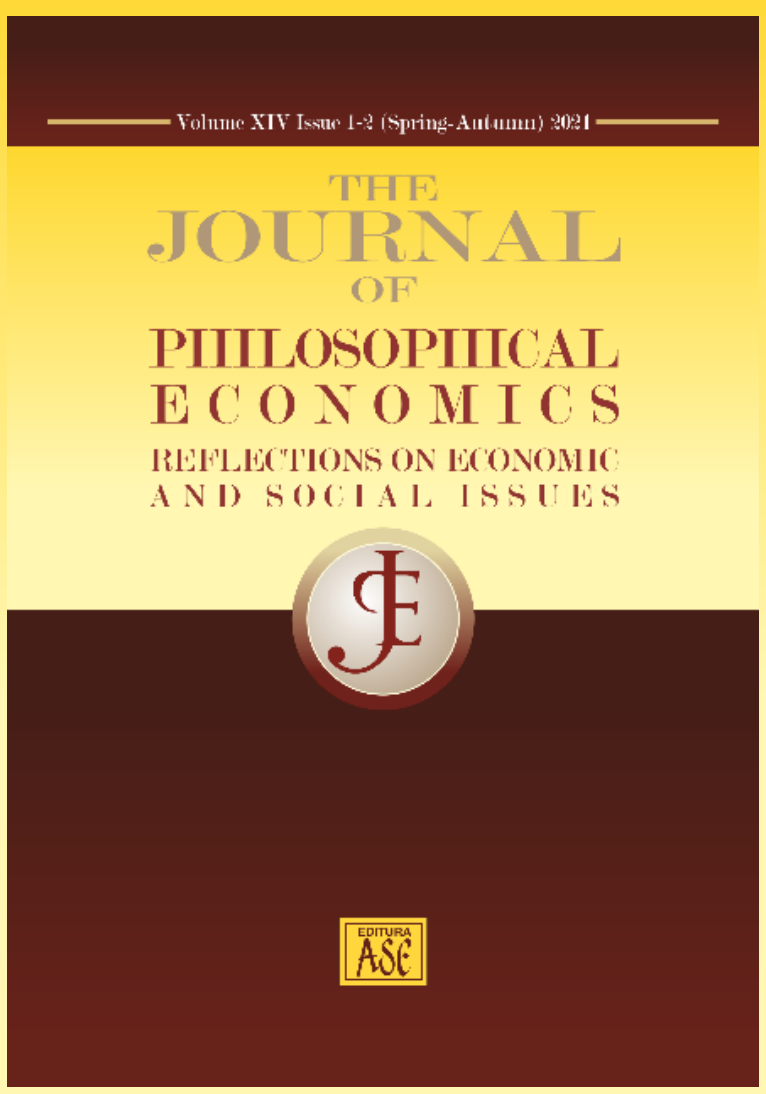

Review of Stephen J. Macekura,

The Mismeasure of Progress: Economic Growth and Its Critics, Chicago and London, The University of Chicago Press, 2020, hb, p. 320, ISBN 978-0-226-73630-3

Dragoș Bîgu 


\title{
Review of Stephen J. Macekura, The Mismeasure of Progress: Economic Growth and Its Critics, Chicago and London, The University of Chicago Press, 2020, hb, p. 320, ISBN 978-0-226-73630-3
}

\author{
Dragoș Bîgu
}

Stephen J. Macekura, an associate professor at the Hamilton Lugar School of Global \& International Studies, Indiana University (USA), presents, from a historical perspective, the history of the idea of gross national product (GNP), from its creation in the 1930 s to the end of the $20^{\text {th }}$ century. The book examines how GNP has been used in public policy for measuring the level of economic activity of a country and explores the main objections to this concept.

One of the most important ideas of this book is that, although fundamental in estimating the level of economic activity of a country and its economic evolution, the concepts of gross national product and gross domestic product (GDP) have been subject to numerous objections. At the same time, the book shows that the choice of using GDP as a main economic indicator and its actual definition are not value-free choices, but ones that are laden with important normative consequences, since the growth of GDP is seen as the most important criterion of economic progress.

The author has a value-free approach, which focuses on the historical description of the concept and on the objections to it. Nevertheless, the whole approach of the volume leads the reader to the idea that a concept whose use could seem unavoidable is just an expression of how economists from a certain historical period conceive the economic system and society's progress. The six chapters of the book focus, in chronological order, on six episodes in the history of GNP, from its creation and introduction in the national statistics to the objections brought at the end of the $20^{\text {th }}$ century.

Received: 11 September 2021 
Bîgu Dragos, (2021), Review of Stephen J. Macekura, The Mismeasure of Progress: Economic Growth and Its Critics, Chicago and London, The University of Chicago Press, 2020, hb, p. 320, ISBN 978-0-226-73630-3, The Journal of Philosophical Economics: Reflections on Economic and Social Issues, XIV (1-2), 256-259

The first chapter presents the origins of the concept of gross national product and the way how it started to be used as an indicator for the level of economic activity. The chapter starts with a brief presentation of the indicators used before 1930s in social statistics and of those built to measure the standard of living. Then, the chapter focuses on the GDP's introduction in national statistics. I think that a more detailed analysis of the economists' debates on the definition of this concept - especially that on whether and how the government spending should be counted in gross national product - would have been useful to understand better the origins of the concept. The second chapter examines the difficulties faced by Great Britain and France in their attempt to measure GNP in their colonies, that were going to become independent states in 1960s. The main problem was that their economy was mostly based on subsistence activities, which could not be adequately estimated, since there was no official information on traded quantities and market prices were absent.

The third chapter focuses on the objection to what Macekura calls the growth paradigm, i.e., the view that economic growth, defined by GNP, is 'desirable, imperative, and essentially limitless' (p. 5). The supporters of this view see GNP as a main indicator of welfare. The chapter discusses two types of critiques: environmental and social. Environmental critiques show that GNP does not reflect the degradation of environment and that the focus on economic growth will lead to resource exhaustion and pollution. Social critics argue that the focus on growth produced a society characterized by a preoccupation with productivity and consumerism, which eventually will hinder human freedom. Even to a greater degree, GNP is not adequate for the Third World countries since GNP growth is often joined by increasing levels of inequality and it does not ensure a country's development. Some economists raised a direct objection to the growth paradigm and argue that the pursuit of economic growth was misguided. The Romanian economist Nicholas Georgescu-Roegen was a key figure for this view, by showing that the standard economic theory does not incorporate the biophysical dimension of life. His view and other similar ones were briefly presented in the last part of the chapter. The view that economy is embedded in the natural world leads to the creation of a new economic discipline: ecological economics. 
Bîgu Dragos (2021), Review of Stephen J. Macekura, The Mismeasure of Progress: Economic Growth and Its Critics, Chicago and London, The University of Chicago Press, 2020, hb, p. 320, ISBN 978-0-226-73630-3, The Journal of Philosophical Economics: Reflections on Economic and Social Issues, XIV (1-2), 256-259

The fourth chapter focuses on the movement against growth paradigm that was originated in The Limits of Growth, a very influential report commissioned by the Club of Rome and published in 1972, which argues that the world needs substantial change in resource consumption in order to avoid decline in population and industrial capacity. Macekura shows how the growth paradigm led to a dramatic increase in energy use and how the strong population growth will lead to overconsumption and pollution. Some economists conclude that the only solution is the transition to a system focused on stability and conservation. They state that a new international governing order is needed to establish a more equitable system, in which all people could benefit from the economic development.

The fifth chapter discusses some proposals to improve GNP as an economic indicator. The first section discusses how some indicators were used, because GNP is not a good indicator of quality of life. These quality-of-life indicators were designed to supplement rather to replace GNP. The main problem with these indicators is that they do not start from an agreed characterization of quality of life. Such a characterization is difficult to achieve, and this is the main reason why such indicators are not as carefully followed and considered as GNP. However, the use of some quality-of-life indicators does not represent a serious objection to GNP: if we don't require too much from a single indicator, we can accept that other indicators can also be useful. The second section of the chapter examines the solutions that were proposed to incorporate unwaged labour. This is important not only because the standard formula underestimates GNP, but also because economic growth is artificially increased when subsistence unwaged labour is replaced by paid labour. At the same time, incorporating household labour in GNP would mean a sign of recognition for women, who perform most of this type of labour. The last section deals with some attempts to incorporate pollution and resource use in GNP calculation.

The sixth chapter is devoted to the debates on GNP at the end of the $20^{\text {th }}$ century. The chapter looks at some alternative measures of wellbeing, such as Human Development Index (HDI), Genuine Progress Indicator (GPI) and Gross National Happiness. Among these, only the first indicator has achieved a certain importance as a measure of development. The chapter also examines how, in the 
Bîgu Dragos, (2021), Review of Stephen J. Macekura, The Mismeasure of Progress: Economic Growth and Its Critics, Chicago and London, The University of Chicago Press, 2020, hb, p. 320, ISBN 978-0-226-73630-3, The Journal of Philosophical Economics: Reflections on Economic and Social Issues, XIV (1-2), 256-259

1970s, in the developed countries, the economic growth was considered again the main goal of economic policy. The last part of the chapter provides a cursory overview of the efforts to take into account natural degradation and unwaged labour in GDP. An important episode in the history of economic growth is the transition from GNP to GDP as a central measure of economic activity of a country. This episode deserves a more careful treatment.

Macekura shows that the choice of gross national product as the main concept for measuring the level of economic activity of a country has significant consequences. The choice to use some concepts and to gather some data is not neutral, but it comes with a set of assumptions on what is important for the society and for characterizing its progress. For instance, as the author shows (p.6), Kuznets, one of the creators of the concept of gross national product, argued that spending on armament should not be counted as a part of gross national product, in order not to give governments a perverse incentive to increase military spending. At the same time, some economists consider that unwaged women's domestic labour should be counted in national gross product and made efforts to quantify it. These positions are implicit proof of the fact that the decision to include or exclude the output of some activities from national product is value laden. Another element, which is not discussed in the book, is also important. The decision whether to include some activities in the estimation of gross national product is driven also by practical circumstances. Thus, not including unwaged labour in GNP and GDP is also the result of the fact that its measurement would be very difficult and subject to unavoidable debates. These practical difficulties to measure unwaged labour and environmental degradation explain why, despite the significant objections that are discussed throughout the book, the concept of gross domestic product, in its actual definition, has preserved its central position in economic statistics.

Dragoș Bîgu is senior lecturer of business ethics and academic ethics at the Bucharest University of Economic Studies (dragos.bigu@man.ase.ro). 